COMMENT. The authors propose that their fMRI findings are compatible with a bilaterally distributed sensorimotor system in the preterm infant. The reductions of oxy/deoxy- $\mathrm{Hb}$ ratio in activated brain tissue may reflect ineffective neural processing during this maturational stage of rapid synapse formation. Positive blood oxygenation leveldependent responses or failure to activate the sensorimotor cortex in a preterm infant may predict abnormal cerebral development and need for careful follow-up. fMRI should provide a more effective measure of long-term developmental problems than the neonatal neurological exam.

\title{
CONGENITAL HYDROCEPHALUS RISK FACTORS
}

Risk factors associated with the pathogenesis of congenital hydrocephalus were evaluated in a 10 year retrospective study of 596 cases identified at the University of Mississippi Medical Center between 1998 and 2007. Significant risk factors included lack of prenatal care, multiparous gestation, maternal diabetes, maternal chronic hypertension, pregnancy-induced hypertension, and alcohol use during pregnancy. Hydrocephalus was familial in $12 \%$ cases. Except for an increased incidence of multiparous pregnancies and prenatal care in the first trimester in familial cases, no differences in risk factors were identified between sporadic and familial congenital hydrocephalus. The prevalence of familial cases within this cohort is much higher than that reported in X linked congenital hydrocephalus (2-7\%), and suggests that the strong genetic factor in etiology is attributed to non-X linked patterns of inheritance. (Landingham MV, Nguyen TV, Roberts A, Parent AD, Zhang J. Risk factors of congenital hydrocephalus: a 10 year retrospective study. J Neurol Neurosurg Psychiatry February 2009;80:213-217). (Respond: Dr J Zhang, Department of Neurosurgery, University of Mississippi Medical Center, 2500 N State St, Jackson, MS 39216. E-mail: jhzhang@neurosurgery.umsmed.edu).

COMMENT. Both genetic and environmental factors are involved in the pathogenesis of congenital hydrocephalus. Some risk factors identified in this study should be susceptible to preventive measures, including improved prenatal care and nutrition, avoidance of alcohol, and prompt treatment of hypertension.

\section{MODERATE PREMATURITY AND RISKS FOR CEREBRAL PALSY}

The association between moderate prematurity and the incidence of adverse neurodevelopmental outcomes was assessed in a cohort of infants born in the Kaiser Permanente Medical Care Program of Northern California. Data covered 141,321 children born at $>30$ weeks gestation between Jan 1, 2000 and June 30, 2004, followed through Jan 30, 2005. Decreasing gestational age was associated with increased incidence of cerebral palsy (CP) and developmental delay (DD), even in those born at 34 to 36 weeks gestation. Late preterm infants were $>3$ times as likely to have $\mathrm{CP}$ as term infants. Children born at 34 to 36 weeks were marginally at higher risk of DD and mental retardation but not seizures. (Petrini JR, Dias T, McCormick MC, Massolo ML, Green NS, Escobar GJ. Increased risk of adverse neurological development for late preterm infants. J Pediatr February 2009;154:169-176). (Reprints: Joann R Petrini PhD MPH, March of Dimes National Office, 1275 Mamaroneck Ave, White Plains, NY 10605. E-mail: JPetrini@marchofdimes.com). 